\title{
Object-oriented Design Framework for Stock Keeping Unit Generating System
}

\author{
Khabbazi M. R. ${ }^{a *}$, Shapi'i A. ${ }^{a}$, Hasan M. K. ${ }^{a}$, Sulaiman R. ${ }^{b}$, Eskandari, A. ${ }^{\text {, }}$ Taei-Zadeh, A. ${ }^{a}$ \\ ${ }^{a}$ Department of Industrial Computing, FTSM, University Kebangsaan Malaysia, Bangi, Malaysia \\ bInstitute of Visual Informatics, FTSM, University Kebangsaan Malaysia, Bangi, Malaysia \\ 'Graduate School of Business, University Kebangsaan Malaysia, Bangi, Malaysia
}

*Corresponding author: mrkabbazi@gmail.com

\section{Article history}

Received :20 January 2013

Received in revised form :

10 June 2013

Accepted :15 June 2013

Graphical abstract

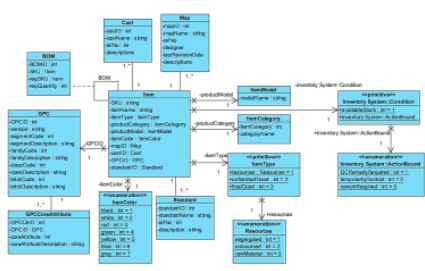

\begin{abstract}
This paper proposes an object-oriented design for generating Stock Keeping Unit coding system. Through recognition and analysis of the inventory item particulars and conceptualizing the important classes as one package, the framework is developed in a modular-basis able to be integrated with other parts of the system. Using UML class and package diagram as of the best practice in object-oriented, conducting the analysis and design is elaborately discussed. A prototype implementation is carried out to support the designed framework over its applicability at a modular information system. Moreover, the item particular package with unique and organized SKU numbering system efficiently supports the fundamental need of item identification at inventory control operations and classification and guarantees different types of reports and lookups.
\end{abstract}

Keywords: Inventory management; object oriented; stock keeping unit; UML

\begin{abstract}
Abstrak
Kertas ini mencadangkan satu reka bentuk berorientasikan objek untuk menjana Saham Unit Mengekalkan sistem kod. Melalui pengiktirafan dan analisis butir-butir item inventori dan conceptualizing kelas penting sebagai satu pakej, rangka kerja itu dibangunkan dalam asas modular dapat diintegrasikan dengan bahagian-bahagian lain sistem. Menggunakan UML kelas dan rajah pakej sebagai amalan terbaik dalam berorientasi objek, menjalankan analisis dan reka bentuk penuh dibincangkan. Satu pelaksanaan prototaip dijalankan untuk menyokong rangka kerja yang direka atas penggunaannya pada sistem maklumat modular. Selain itu, pakej item tertentu dengan sistem penomboran yang unik dan teratur SKU cekap menyokong keperluan asas pengenalan item di operasi kawalan inventori dan klasifikasi dan menjamin jenis laporan dan lookup.
\end{abstract}

Kata kunci: Pengurusan inventori; berorientasikan objek; unit stok menjaga; UML

(C) 2013 Penerbit UTM Press. All rights reserved.

\subsection{INTRODUCTION}

Inventory management is an inseparable part of the larger practice of logistics within supply chain management $[1,2]$. Successful inventory management system provides a unique and meaningful code for each storable item type called Stock Keeping Unit (SKU) referring to different instance of the same item. This coding system basically contains related item characteristic data that are distinguished as significant in respect to the aim and application of SKUs [3]. An automatic integrable SKU generating system is indispensably seen as the advantageous, enabling the inventory system to make rightful decisions at different situations such as item classification as well as systematically tracking product availability, production planning, and inventory control system applications.
As a part of a comprehensive research over integrated inbound and outbound logistics system in a modular and web-based design, this paper aims to propose an object-oriented framework design for SKU coding generating system in which the integration with other parts of the system is possible and advantageous. The design of system is carried out with the practices in objectoriented design using UML class and package diagrams. All important characteristics of the item particulars are identified and SKU classifiers are elaborately conceptualized to be used at a modular basis system.

The reminder of this paper is as follows. Item identification paradigm is discussed next followed by the item classification section. Next, the development of object-oriented framework for SKU coding system is elaborated including item particular class and package diagrams. Eventually, the prototype implementation is explained and followed by the conclusion. 


\subsection{ITEM IDENTIFICATION}

To identify a particular item and its related information at inventory management and control, a unique identifier system is applied. The unique identifiers are basically made of several digit numbers, letters, or a combination of both. There are two main domains of item identification system with distinctive pattern for each including (1) internal using SKU, Serial-numbers, etc., and (2) external or universal businesses using barcode standards such as EAN/UPC, GS1 DataBar, and EPCglobal standards to be used at RFID.

SKU is basically an alphanumeric code uniquely designed for the enterprise based on either its internal policies or third-party regulations or sometimes regional strategies on data storage/retrieval. Therefore, an identical product may have different SKUs if sold by different companies. In the other hand at external businesses, item identification system depending on the application follows a set of standards using appropriate barcode types having different strengths or weaknesses to represent a unique identified item or item type. Table 1 illustrates a summarized overview of all item identification standards which are the most widely used standards basically for external performances designed to improve the supply chain management globally provided by GS1 association [4].

Table 1 Overview of item identification standards

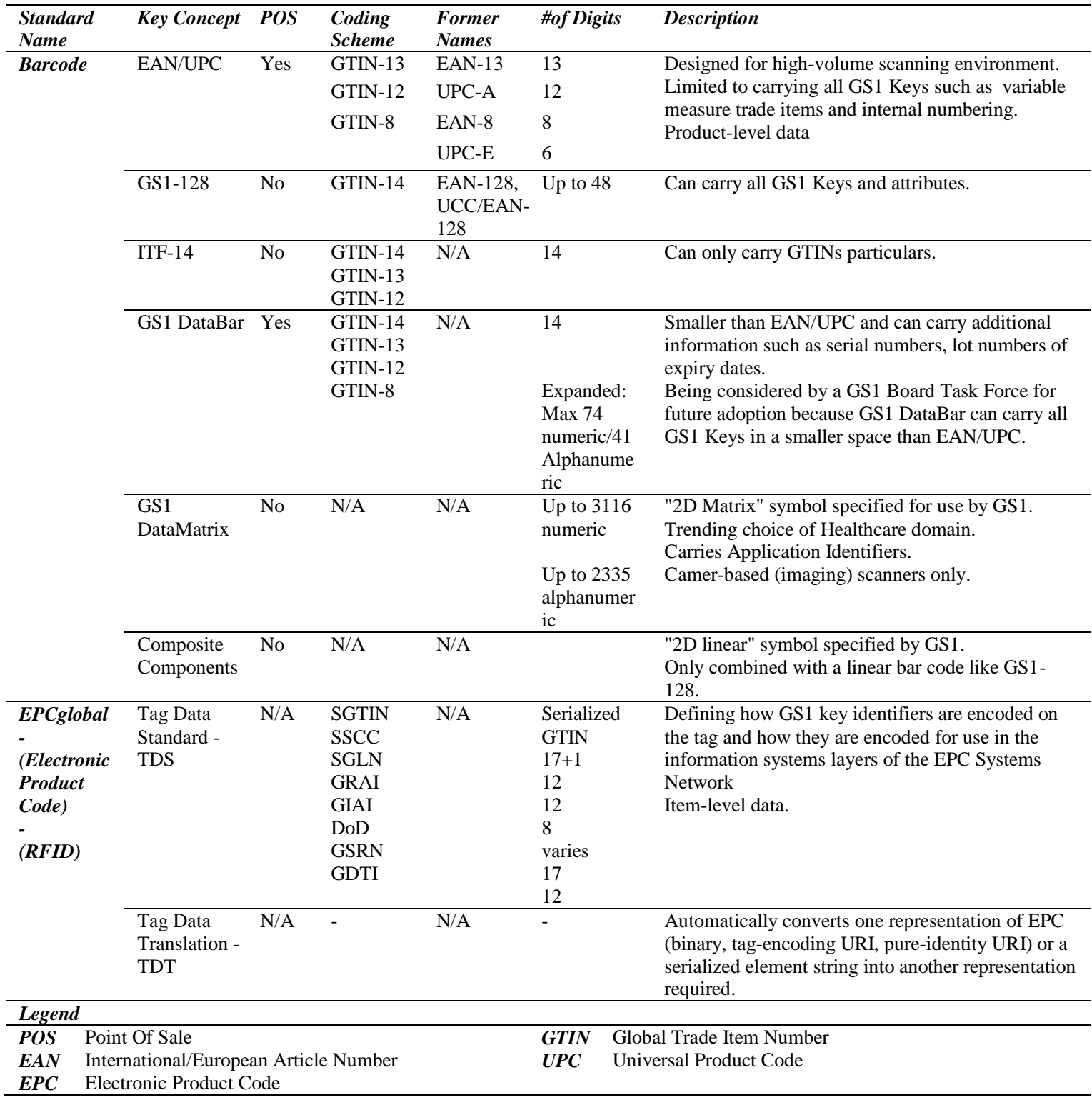

There are several other automatic identification tools and techniques which are mainly failed to become universally applicable and less practiced because of the affordability and compatibility issues such as OCR, vision recognitions, magnetic inks, smart cards, contact memory technologies, magnetic stripes, and Bluetooth [5]. The selection of these standards and technologies is made under certain circumstances and determined by a number of factors depending to the item 
properties itself [6]. After all, an immense number of studies over resolving the issues at application of Barcode and RFID technology in the industry or history, trend and reviews can be found [to name a few see: $6,7,8-12]$.

\subsection{ITEM CLASSIFICATION}

In inventory control management there are general concerns about classification of items. These classifications are generally based on the level of defined importance for the item [13]. However, the criterion that what is important for an enterprise with respect to inventory items differs. "SKU classification" term in material and stock management is generally used to select inventory control policies and the classes are determined based on different type of inventory categorization techniques such as $\mathrm{ABC}$. As an overview, Kampen et al. [3] proposes a framework with four elements of the aim of the classification, the contexts, the item characteristics, and the technique to classify the SKUs. The classes are identified not only based on the importance of the item such as cost or maintenance but are determined through impact of distinguished four interrelated elements [3]. There are several studies of how to determine the optimum amount of classes or how to define the class boundaries in the literature [for example: 14, 15-20].

Classifying SKU is often not an aim itself but for the purpose of the company's application systems such as Production, Quality, Sale, Warehouse, and Shipping. The concept of item classification in here is at internal performances by automatic SKU generation system which could be integrated and utilized efficiently with other management information systems. In global perspective, the product classification is made through Global Product Classification (GPC) standard by mandatory classification system for the Global Data Synchronization Network (GDSN) to enable product search, view, and validation, as well as publication and subscription match by buyers and sellers [for further study see: 21 ]

\subsection{OBJECT-ORIENTED SKU DESIGN}

The object-oriented paradigm for SKU generation system is based on an analysis of item characteristics and the data structure used by them. Relevant entities of item type, category, name, etc. are treated as objects, which generically defined as a class. Each class is associated with a set of attributes that characterizes the identity of objects, and specific instances of classes are known as the objects. As result, the classifiers of Item particulars are identified and conceptualized into UML class diagram as well as analysing the Item particulars accessibility in the modular inbound and outbound e-logistics system through UML package diagram. Designed SKU framework is the basis for automatic SKU coding generation which is verified through a prototype implementation. Next, a modular SKU information system using MS Access as the database platform is carried out to provide a prototype implementation to illustrate the applicability of the designed framework at providing systematic SKU coding system.

\subsection{Item Particular Class Diagram}

Inventory item is defined as a resource or as a processed identifiable object which can be stored and measured [22]. Processed object can be a final good or a semi-finished part that might be used later. Resources can be either as raw material, outsourced (e.g. semi-finished part), or quality-rated final goods
/ semi-finished part. Therefore, the SKUs are categorized as three types of inventory items named as Item Types of: (1) resources such as raw material, outsourced, segregated, (2) unfinished goods such as work-in-process, (3) available stock or finished goods. The other dynamic characteristics that an item might contain such as action bound conditions or ratings (e.g. rework, temporarily docked, QC remedy suppliant) are considered as item condition addressed at Inventory System module. As such, Item class with a unique ID called SKU is defined and customized depending to the enterprise products characteristics.

SKU as a coding system serves basically at tracking and tracing item information and an efficient organized IT-oriented SKU system provides the integrated information system with a real-time inventory control capability. This coding system usually appends item particulars IDs in some sort to achieve one unique specific alphanumeric code for an item. Therefore, item particulars that generally are contributed to the SKU numbers should provide a reference to trace item characteristics such as Item Name, Item Type, Product Category, Product Model, Item Color, etc.

Figure 1 illustrates the SKU generation framework with UML class diagram showing Item particular classes with attributes and associated data types and the relationships among them. "SKU: string" implies that this unique ID could be as alphanumeric digits a combination of letters and numbers. For all Item class attributes, other than "string" data type, the rest are associated to their defined data type particular Classes. Some of the data type Classes are defined as <<primitive >> like ItemType or as <<enumeration〉> such as ItemColor. List of related Item maps, casts, standards, and models are reposited at related classes. Global product classification standard (GPC) class is associated with Item class to be used once applicable.

"Resources" as one ItemType are enumerated as segregated, outsourced, and rawMaterial. Segregated and Outsourced are considered as resources no matter if they are value-added unfinished goods. This helps production planning to achieve a smoother operation at allocating the resources to the "work order" process. If segregated items are considered as rated finished goods then they would be considered as finished goods with condition of available stocks stored at the warehouse.

Stored items at Warehouse are classified as: availableStock and actionBound items. Items with uncertain condition of "ActionBound" are primarily stored at the Warehouse until the decisions are made for them. "ActionBound" are enumerated as TemporarilyDocked, QCRemedyRequired, and ReworkRequired. Segregation operation as a decision to be made for ActionBound items results in generation of Items with ItemTypes of either as Resources (i.e. Segregated) or FinishedGood or Discard items.

"UnfinishedGoods" are value-added resources. They are those items in such a state that they can be measured, identified and stored while they can be treated neither as resources nor as finished products. They have no particular decision-needed conditions therefore these items are considered as another alternative for item characteristics in ItemType category.

Besides, Item Class has "Self-association" to itself meaning that an item can be composed of other items looking upward or it might be consumed by other items at a downward view. 


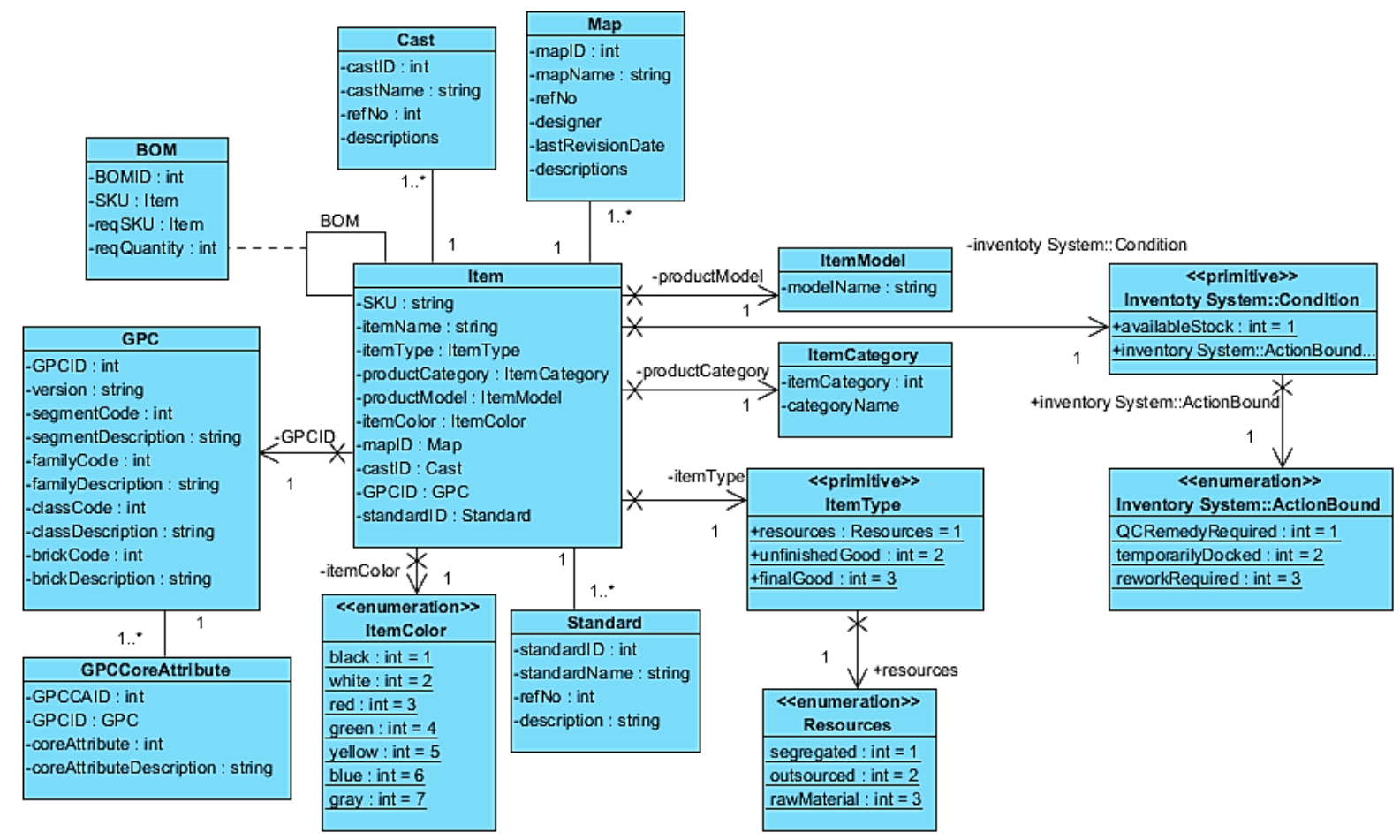

Figure 1 Item particular class diagram

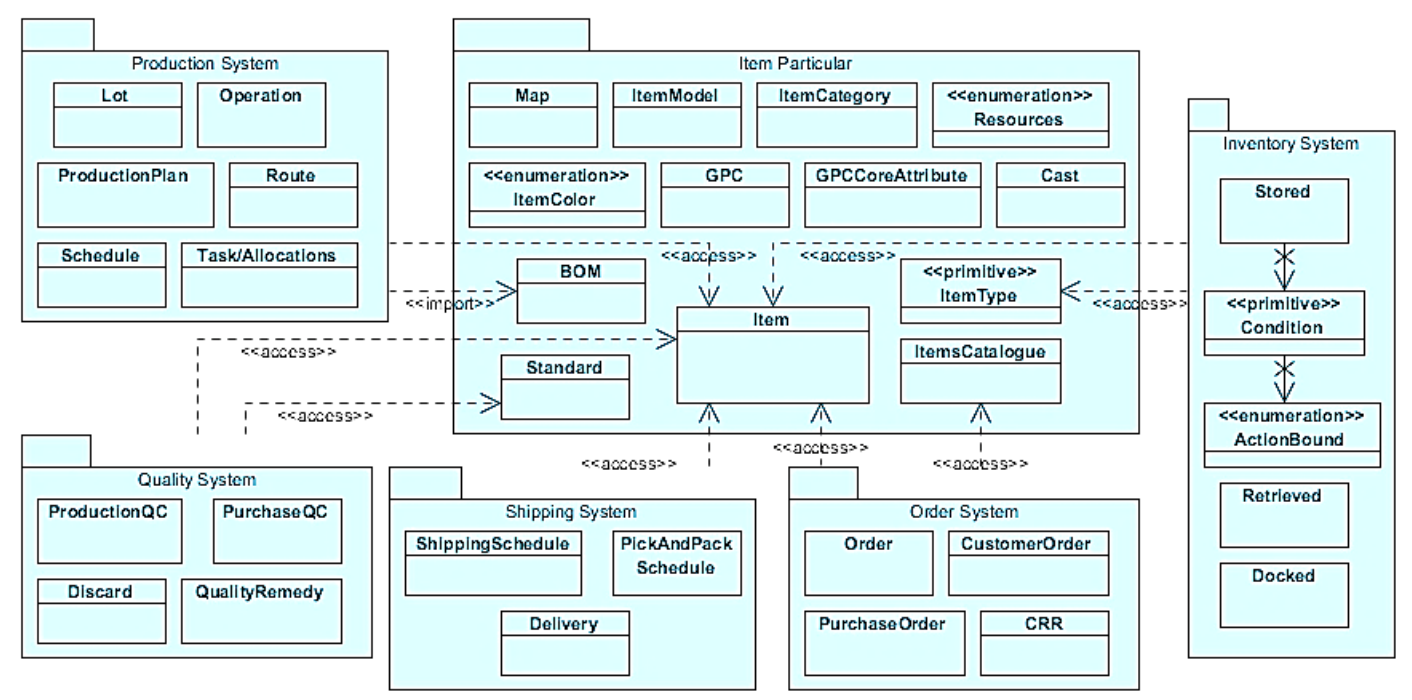

Figure 2 Item particular package diagram

BOM (Bill Of Material) Class is an "Association class" identified for self-association relationship. With ReqSKU and ReqQuantity attributes now the "Self-association" is more meaningful describing the requested item and required quantity for composition of particular SKU number (i.e. one particular item). <<primitive〉> Condition class and <<enummeration〉> ActionBound class classify the condition of the items. These important characteristics of an item are dynamic and are not going to be used at SKU generation coding system nonetheless are taken to account at characteristics of stored item and Inventory System::Stored class as it is shown yet at Figure 1. Through precise definition of BOM class and Item Class, the designed framework can efficiently cooperate with numerous applications of inbound and outbound logistics system.

\subsection{Item Particular Package Diagram}

The package diagram depicted at Figure 2 displays all the dependency relationships between identified inbound and outbound logistics system packages with the identified classes at Item Particular package. Only dependent contributed classes at each module are displayed of which are provided by accessing or importing data from item particular package classes. Item particulars classes are to address all the static characteristics of the items to generate SKU numbers. The SKU conditions significantly considered as item dynamic data which are basically characterized at inventory system module. The <<import>> dependency relationship between Production system and BOM class implies the publicity of BOM class to Production system in contrary with the <<access $>>$ dependency 
relationship which only provides the access to the referable required SKU number for other classes in different modules.

\subsection{PROTOTYPE IMPLEMENTATION}

Based on designed SKU generating framework, Item particular information system is developed using MS Access as an affordable database platform able to be integrated with other parts of the system [23]. Figure 3 displays a screenshot of contributing designed Tables, Fields, and relationships among them focusing on the Item particular package. SKU Field as the primary key at Item Table is referred as the foreign key providing meaningful item specifications for other Tables. The Item_1 Table implies the "many-to-many" relationship between Item and BOM Tables.

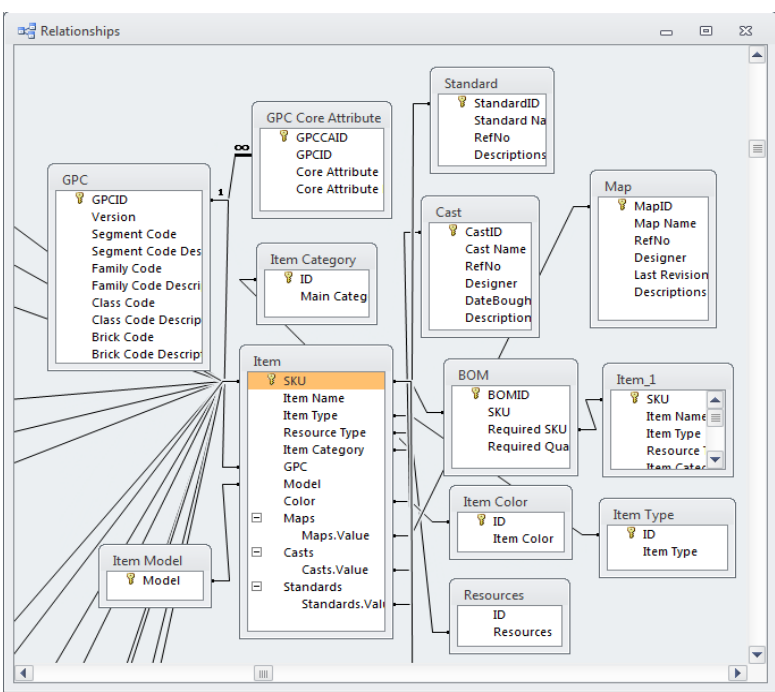

Figure 3 Item particular Item particular package relationships screenshot

To generate the SKU automatically, Item properties are registered first and followed by running an "Update Query" named as Update SKU recorded at Field: SKU, Table: Item, and Updated to: [Item]![Item Type] \& [Item]![Resource Type] \& [Item]![Product Category] \& [Item]![Model] \& [Item]![Color] $\&$ "(" \& [Item]![GPC] \& "). Figure 4 and Figure 5 display the screenshots of the Update SKU Query as well Item Form at generating the SKU number of "306S118(2)" for the finished product of "skid plate $5 * 8$ ". The digit number within the parenthesis at the end of the SKU indicates the availability of the GPC for the item and referring number indicates the associated record within the designed system.

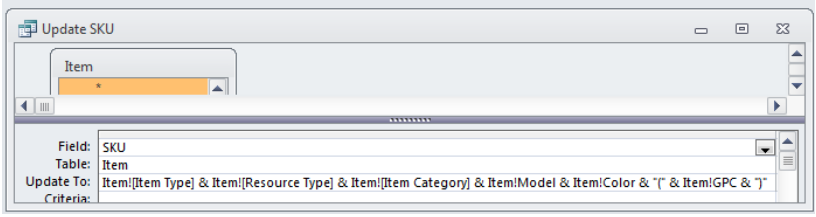

Figure 4 Screenshot of update SKU design query

The required SKUs and its amount either as assembly components or prerequisite item to produce any particular SKU are registered at a sub-form named as BOM. However, tracing the whole list of BOM for a particular SKU can be done through predefined queries. Figure 6 depicts a screenshot of the structure of all associated queries for BOM forward and backward lookups.

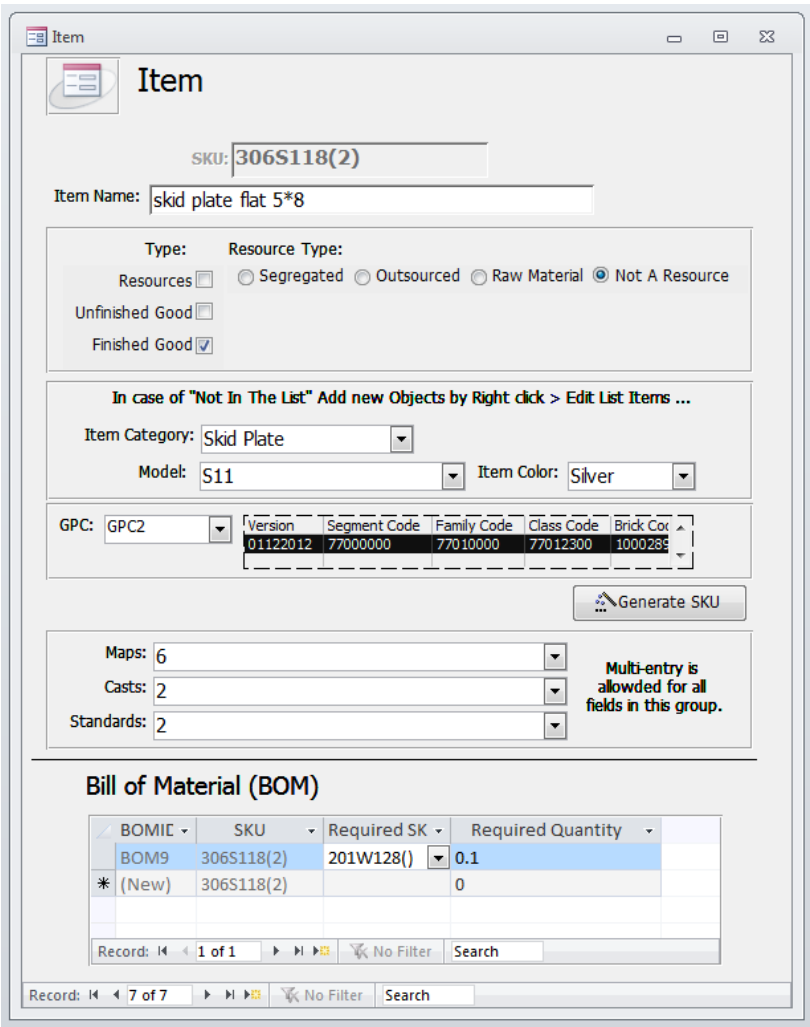

Figure 5 Item form screenshot

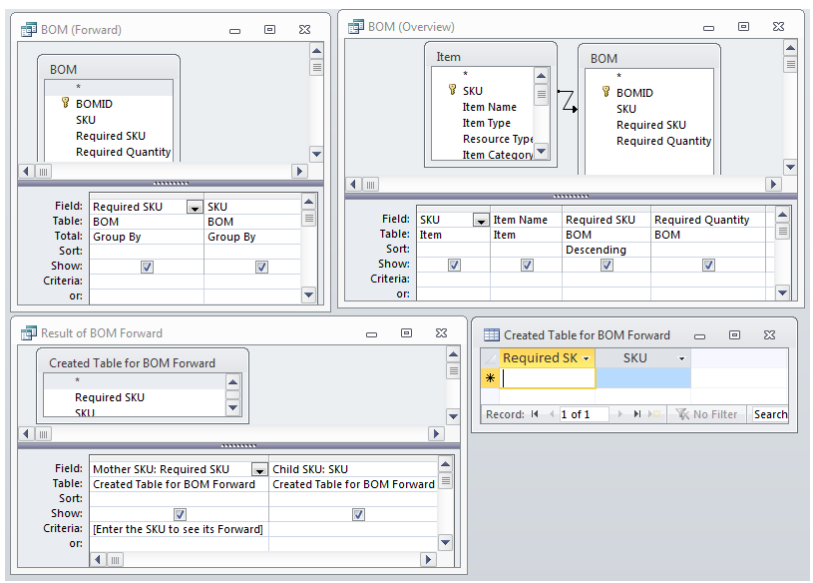

Figure 6 Screenshot of BOM design queries

At running the BOM (Forward), a Macro is launched to run a "Make Table" Query to list all the SKUs and associated required SKUs which is followed by running a "Select" Query from generated Table to filter the results into desired SKU number achieving down-stream SKUs for a particular SKU. There are several other desirable lookups or reports can be made and get the benefits from automated SKU system using query system. Figure 7 displays a screenshot of Item Particular 
Switchboard including provided lookup list like Detailed SKU, Item Catalogue, Item Resume, and so on.

\begin{tabular}{|c|c|}
\hline Forms & \\
Item & \\
BOM & Item Particular Switchboard \\
Maps & Item Resumee \\
Standards & SKU Details (Overview) \\
Casts & Item Catalouge \\
GPC & BOM (Overview) \\
BOM (Backward) \\
Ad Hoc Update & BOM (Foreward) \\
Generate SKU & Maps (SKU) \\
& Standards (SKU) \\
& Casts (SKU) \\
& GPC (Overview) \\
\hline
\end{tabular}

Figure 7 Screenshot of item particular switchboard

\subsection{CONCLUSION}

This paper proposes an object-oriented design for generating Stock Keeping Unit coding system. Using the proposed framework and through following the conducted object-oriented modeling development used in this paper, any specific SKU generating mechanism is systematically achievable. In this paper, all important characteristics of the item particulars are identified and SKU classifiers are elaborately conceptualized in a modular basis system. The object-oriented SKU generating design is practiced using UML class and package diagrams. Designed SKU framework is the basis for automatic SKU coding generation which is verified through a prototype implementation. Using MS Access as the database platform, a modular SKU information system is carried out based on the designed SKU framework offering systematic SKU automatically. Moreover, it supports several significant SKU lookups applicable at other modules such as inventory control, order management, production planning, and etc. Regarding the modular-basis system development, conducting the proposed framework analysis and design stands novel through enabling the integration with other conceptual models or physical datamodels. As the future work, considering the degree of importance of items into the SKU coding system as the result of any SKU classification system such as $\mathrm{ABC}$, seen valuable at dynamic inventory control system application.

\section{References}

[1] Lee, H. T. and J. C. Wu. 2006. A study on Inventory Replenishment Policies in a Two-Echelon Supply Chain System. Computers \& Industrial Engineering. 51: 257-263.

[2] Sana, S. S. 2012. A collaborating Inventory Model in a Supply Chain Economic Modelling. 29: 2016-2023.
[3] Kampen, T. J. v., R. Akkerman and D. P. v. Donk. 2012. SKU Classification: A Literature Review and Conceptual Framework. International Journal of Operations \& Production Management. 32(7): 850-876.

[4] GS1a. 2012. (December). GS1 - The global language of Business. Available: http://www.gs1.org/.

[5] Kärkkäinen, M. and T. Ala-Risku. 2003. Automatic Identification Applications and Technologies. Logistics Research Network (LRN): 8th Annual Conference. London, UK.

[6] Hong-ying, S. 2009. The Application of Barcode Technology in Logistics and Warehouse Management. ETCS' 09, First International Workshop on Education Technology and Computer Science. Wuhan, Hubei, IEEE. 732- 735 .

[7] Er, Z., F. Y. Lian and J. G. Lian. 2008. An RFID-based Automatic Identification System on Modern Grain Logistics. ICMCEG International Conference on Management of e-Commerce and eGovernment IEEE Computer Society. 10-13.

[8] Sahin, E., Y. Dallery and S. Gershwn. 2002. Performance Evaluation of Traceability System: An Application of the Radio Frequency Identification Technology. IEEE International conference on Systems, Man and Cybernetics. Ecole Centrale de Paris, France, IEEE.

[9] Wang, K., Y. Zou and H. Wang. 2005. Barcode Reading from Images Captured by Camera Phones. 2nd International Conference on Applications and Systems. Guangzhou IEEE. 6.

[10] Angeles, R. 2009. Anticipated IT Infrastructure and Supply Chain Integration Capabilities for RFID and Their Associated Deployment Outcomes. International Journal of Information Management. 29(3): 219-231.

[11] Ngai, E. W. T., K. K. L. Moon, F. J. Riggins and C. Y. Yi. 2008. RFID Research: An Academic Literature Review (1995-2005) and Future Research Directions. International Journal of Production Economics. 112(2): 510-520.

[12] McFarlane, D. and Y. Sheffi. 2002. The Impact of Automatic Identification on Supply Chain Operations. The International Journal of Logistics Management. 14(1): 1-17.

[13] Vries, J. d. 2007. Diagnosing Inventory Management Systems: An Empirical Evaluation of a Conceptual Approach. International Journal of Production Economics. 108: 63-73.

[14] Bacchetti, A., F.Plebani, N.Saccani and A.A.Syntetos. 2012 Empirically-Driven Hierarchical Classification of Stock Keeping Units. International Journal of Production Economics. Available online - In Press.

[15] Heinecke, G., A.A.Syntetos and W.Wangd. 2011. Forecasting-based SKU classification. International Journal of Production Economics. Available online - In press

[16] Yu, M.-C. 2011. Multi-criteria ABC analysis Using Artificialintelligence-based Classification Techniques. Expert System with Applications. 38: 3416-3421.

[17] Chandra, C. and S. Kumar. 2001. Taxonomy of Inventory Policies for Supply-chain Effectiveness. International Journal of Retails and Distribution Management. 29(4): 164-175.

[18] Byrne, B. 2007. Finally, a Strategic Way to Cut Unnecessary SKUs. Strategy \& Leadership. 35(1): 30-35.

[19] Shapiro, J. F. and S. N. Wagner. 2009. Strategic Inventory Optimization. Journal of Business Logistics 30(2): 161-173.

[20] Rezaei, J. and S. Dowlatshahi. 2010. A Rule-based Multi-criteria Approach to Inventory Classification. International Journal of Production Research. 48(23): 7107-7126.

[21] GS1b. 2012. (December). Global Procut Code standards. Available: http://www.gs1.org/gsmp/kc/gpc.

[22] Khabbazi, M. R., M. Y. Ismail, N. Ismail, S. A. Mousavi and H. S. Mirsanei. 2011. Lot-base Traceability Requirements and Functionality Evaluation for Small- To Medium-Sized Enterprises. International Journal of Production Research. 49(3): 731-746.

[23] Khabbazi, M. R., M. K. Hasan, R. Sulaiman and S. A. Mousavi. 2010. Extending Quality Data for Lot-Based Traceability System in SME. Information Technology (ITSim), 2010 International Symposium in. Kuala Lumpur, Malaysia, IEEE. 1158-1163. 